\title{
Advances in and Algorithms for the Treatment of Relapsing-Remitting Multiple Sclerosis
}

\author{
Jens Ingwersen ${ }^{1} \cdot$ Orhan Aktas $^{1} \cdot$ Hans-Peter Hartung ${ }^{1}$
}

Published online: 23 December 2015

(C) The American Society for Experimental NeuroTherapeutics, Inc. 2015

\begin{abstract}
Treatment options in relapsing-remitting multiple sclerosis have increased considerably in recent years; currently, a dozen different preparations of diseasemodifying therapies are available and some more are expected to be marketed soon. For the treating neurologist this broad therapeutic repertoire not only greatly improves individualized management of the disease, but also makes choices more complex and difficult. A number of factors must be considered, including disease activity and severity, safety profile, and patient preference. We here discuss the currently existing options and suggest treatment algorithms for managing relapsing-remitting multiple sclerosis.
\end{abstract}

Key Words Relapsing-remitting multiple sclerosis . Disease-modifying therapy $\cdot$ Treatment decisions . Treatment algorithm

Since the emergence of interferon- $\beta$ and glatiramer acetate (GA) in the early and mid-1990s the treatment of relapsingremitting multiple sclerosis (RR-MS) was rather simple for many years, the 2 compound classes being the only approved therapies. In recent years, however, numerous options with very different mechanisms of action, efficacy, and safety profiles, and also differing features concerning patient convenience, have entered the market. For the treating neurologist, as well as the patient, the resulting options are becoming increasingly challenging. We here summarize the current disease-

Hans-Peter Hartung

hans-peter.hartung@uni-duesseldorf.de

1 Department of Neurology, Medical Faculty, University Hospital, Heinrich Heine University Düsseldorf, Düsseldorf, Germany modifying therapies (DMTs) in terms of efficacy and safety profile and propose a treatment algorithm. Several new drugs are imminently emerging and will be subject to another review in this issue and thus not be discussed in detail here $[1,2]$.

\section{Currently Approved Drugs for RR-MS: First-line DMTs}

\section{IFN- $\beta$}

In 1993, subcutaneous IFN-1 $\beta$ (Betaseron/Betaferon: Bayer HealthCare Pharmaceuticals, Berlin, Germany and later also Extavia: Novartis Pharma, Basel, Switzerland) was the first preventive drug approved for RR-MS and has since been the mainstay of RR-MS treatment [3]. Several similar preparations have been marketed since, namely intramuscular IFN$1 \beta a$ (Avonex: Biogen, Cambridge, MA) [4], subcutaneous IFN-1 $\beta$ a (Rebif: Merck, Darmstadt, Germany) [5], and, more recently, pegylated IFN-1 $\beta$ a (pegIFN-1 $\beta a$; Plegridy: Biogen, Cambridge, MA) [6]. They differ mainly in terms of application route and frequency (s.c. $v s$ i.m.; once-daily to once every other week; different application devices). Across studies, efficacy is roughly $30 \%$ in terms of decrease in annualized relapse rate. Comparative data between IFNs are scarce and overall do not show meaningful differences with regard to efficacy [7]. The mechanisms of action probably relate to a multitude of cell-based functions, including induction of regulatory mediators [e.g., interleukin (IL)-10 and IL-4, and others], decreasing proinflammatory cytokines (e.g. IFN- $\gamma$, IL-17, tumor necrosis factor- $\alpha$, osteopontin, and others), and modulating cell trafficking across the blood-brain barrier [8]. The safety profile is quite favorable in terms of severe adverse effects. However, many patients complain about the relatively frequent influenza-like symptoms and injection site reactions. 


\section{GA}

GA followed IFN-1 $\beta$ in 1995 as the second DMT approved for the prevention of MS relapses and is marketed as Copaxone: Teva Pharmaceuticals, Petah Tikva, Israel, initially as once-daily subcutaneous injections [9], and more recently as a 3 times weekly regimen [10]. GA is a mixture of polypeptides derived from 4 amino acids and its mechanisms of action may include a shift from a $\mathrm{T}$ helper 1 cell-driven immune response to a $\mathrm{T}$ helper 2 cell-driven one by interacting with CD4+ and CD8+ T cells, as well as antigen-presenting cells [11]. GA does not induce influenza-like symptoms but cutaneous side effects such as lipoatrophy at the injections site is common [12]. As with the IFNs, it has a favorable safety profile in terms of severe side effects. GA showed beneficial effects on Expanded Disability Status Scale progression, but only trends without reaching formal significance. Even though there is a lack of well-controlled data on pregnancyrelated risks for all DMTs, some data suggest that GA may have the best safety profile among the first-line DMTs with regard to this common patient need. Copaxone received the most favorable Food and Drug Administration (FDA) pregnancy label (category B), but data are considered insufficient and further research seems necessary [13].

\section{Dimethyl Fumarate}

Dimethyl fumarate (DMF; formerly known as BG-12) is the first oral DMT approved in 2013 by both the FDA and European Medicines Agency (EMA) for first-line therapy. The compound, marketed as Tecfidera: Biogen, Cambridge, MA, originates from dermatology, namely psoriasis treatment with fumarate esters. It is given in 2 daily doses. Its mechanism of action has not been completely revealed and is still a matter of discussion. Cytokine modulation and neuroprotective effects mediated via the nuclear factor E2-related factor are likely to play an important role $[14,15]$, as well as hydroxycarboxylic acid receptor 2-regulated invasion of neutrophils into the central nervous system (CNS) [16]. The formulation as delayedrelease DMF was found to be superior to placebo [17-19] and noninferior to the active comparator GA, in 2 large controlled phase III trials [20]. The latter showed a numerically superior effect against the active comparator, although this did not achieve significance (51\% relapse risk reduction compared with placebo for DMF vs $31 \%$ relapse risk reduction compared with placebo for GA). The safety profile includes nonsevere, but potentially unpleasant, side effects such as gastrointestinal irritations and flush symptoms, which in the majority of patients tend to diminish and abate over time; however, there are also more severe, though very rare, side effects. Much attention has been paid to the news that fumarates (used in a similar but differing formulation in psoriasis
$[21,22])$ can, in general, be associated with the occurrence of JC virus (JCV)-induced progressive multifocal leukencephalopathy (PML). PML is a relevant issue, especially in natalizumab treatment (see below), but lately also occurred in patients with MS treated with DMF. One patient from an extension of one of the phase II studies developed PML after long-term low lymphocyte counts, suggesting that lymphocyte counts could be a risk marker [23]. A recent case of PML in DMF in RR-MS, however, apparently developed the infection in the absence of low lymphocyte counts, thus questioning their relevance for risk management [24]. These cases are certainly of concern but in light of the large number of treated patients worldwide, DMF is generally still viewed as a very useful and safe first-line DMT and has become one of the most commonly prescribed DMTs in RR-MS [25, 26].

\section{Teriflunomide}

The most recently approved first-line DMT, teriflunomide, is also an oral drug, the once-daily pill Aubagio: Genzyme, Cambridge, MA. It is the active metabolite of its parent drug leflunomide that has been in use for rheumatoid arthritis since 1998 [27]. Teriflunomide's main mechanism of action is thought to be inhibition of the enzyme dihydroorotate-dehydrogenase and the subsequent inhibition of pyrimidine synthesis. Consequently, this reduces the activity of proliferating (blasting) lymphocytes. It is not supposed to affect homeostatically proliferating hematopoietic cells $[28,29]$. Efficacy was superior to placebo and comparable to intramuscular IFN-1ßa [30-32]. Safety issues include nausea, diarrhea, hair thinning, and elevations in liver enzymes. Drug-related deaths or safety signals of the magnitude of PML have not so far been observed for teriflunomide. However, leflunomide's safety profile is relevant for teriflunomide and some rare serious side effects have been observed with this predecessor drug, including 3 cases of PML (in $>2$ million patient-years of leflunomide use). Two patients had previously been treated with other immunosuppressants $[33,34]$, and there is limited information on the third [35]. A safety concern relevant for many young female patients with MS is the probable teratogenic potential of leflunomide and teriflunomide. For leflunomide, animal studies have demonstrated teratogenicity, prompting great caution with the use of teriflunomide in females with child-bearing potential and a wish to have children. For teriflunomide, pregnancy outcomes were retrospectively evaluated in the global pharmacovigilance database following patients included in clinical phase II and phase III trials and did not indicate a teratogenic potential [36]. Overall, teriflunomide is expected to become a mainstay in disease-modifying treatment of RR-MS [37]. 


\section{Currently Approved Drugs for RR-MS: Second-line DMTs}

\section{Fingolimod}

Fingolimod (Gilenya: Novartis Pharma, Basel, Switzerland) was the first approved oral drug for RR-MS treatment and was initially approved by the FDA in 2010 as a first-line therapy and in 2011 by the EMA as a second-line therapy. It is a firstin-class modulator of lymphocyte migration that binds to the sphingosine-1-phosphate (S1P) receptor on lymphocytes and prevents their egress from lymphatic tissue. It therefore ultimately blocks their invasion into the brain [38, 39]. As fingolimod, as a lipophilic substance, accumulates in fatty tissues, including the CNS and S1P receptors, found on CNS-residing glia cells, direct neuroprotective properties of fingolimod have been suggested [40-42]. While preclinical studies and consistently beneficial effects of fingolimod on atrophy development in phase II and III trials support such an effect, fingolimod failed to show efficacy in primary progressive MS, the pathology of which is thought to be dominated by neurodegeneration [43]. In RR-MS the FREEDOMS and TRANSFORMS studies showed superiority not only to placebo [44-47], but also to the active comparator intramuscular IFN-1ßa [48]. Fingolimod significantly reduced the relapse rate by $38 \%$ and $50 \%$ (for $1.25 \mathrm{mg}$ and $0.5 \mathrm{mg}$ daily, respectively) compared with IFN-1 $\beta$, and several magnetic resonance imaging (MRI) measures consistently favored fingolimod. Both the EMA and FDA approved the drug for second-line use while a considerable proportion of subjects had not been pretreated with another DMT. There are no other direct controlled prospective comparisons to other DMTs, but a recent retrospective database analysis could show that patients switching from IFNs to fingolimod experienced fewer relapses than those switching from IFNs to GA [49]. Furthermore, as efficacy for first-line therapeutics has consistently been around a $30 \%$ reduction in relapse rate (as was the IFN-1 $\beta$ arm in TRANSFORMS), it is generally believed that fingolimod is more efficacious than the IFNs, GA, and teriflunomide (and probably also to DMF, according to indirect comparisons [50]). While controlled prospective studies comparing fingolimod to the other second-line drugs natalizumab and alemtuzumab are completely lacking, a comparison between several placebo-controlled trials, as well as findings from the MSBase registry, lead most to view fingolimod as less effective than the other 2 treatments [51]. There are several safety issues, including cardiac side effects, that result from off-target effects on S1P receptors on cardiomyocytes, with bradycardia and atrioventricular conduction block, and 1 possible fatality after the first dose in the postmarketing phase. Several cases of herpes virus encephalitis (including 2 deaths) and cryptococcal meningitis have been reported in the pivotal studies (including patients treated at a higher dose than later approved) and in postmarketing [52]. Two cases of hemophagocytic syndrome with fatal outcome have been reported recently. In the absence of immunity, varicella zoster virus infections occur with increased frequency but can be prevented by appropriate vaccination before embarking on fingolimod therapy [53]. Finally, there have been several cases of PML under fingolimod, mostly after a switch from natalizumab treatment (where PML risk is a much greater issue), and 3 cases on fingolimod monotherapy [54].

\section{Natalizumab}

Natalizumab is a monoclonal humanized antibody binding and antagonizing $\alpha 4 \beta 1$-integrin. Thereby it inhibits migration of inflammatory cells across the blood-brain barrier. In 2004, natalizumab was first marketed after accelerated approval was granted in light of the urgent need for more efficient therapy at the time and efficacy not seen before. Data from the AFFIRM study showed a relapse risk reduction of $68 \%$ compared with placebo, significant reduction of sustained disability progression, and significant effects in MRI measures [55]. Results obtained in the AFFIRM trial have been used to discuss natalizumab as a first-line medication (the vast majority of patients had not previously been treated with IFNs or GA), whereas both the FDA and EMA approved the drug for second-line use. A second trial (SENTINEL; natalizumab as an add-on to intramuscular IFN-1 $\beta$ a) was terminated because of 2 cases of PML [56, 57], and approval was withdrawn for some time. After no further cases of PML occurred during the studies, natalizumab was re-approved in 2006 for patients with active MS or those not responding to classical injectable DMTs (IFN- $\beta$, GA). Overall clinical experiences, as well as patient registry studies such as the TYSABRI Observational Program or MSBase, confirmed superior efficacy of natalizumab compared with IFN- $\beta$ or GA [58-60]. Since then, however, $>560$ cases of PML have been reported to be associated to natalizumab (as of 4 September 2015, 588 cases out of 142,000 patients treated with natalizumab [61]). The overall risk of PML development under natalizumab seems to be around 2 per 1000 , but several factors could be identified that help to stratify the risk: prior immunosuppressant medication, treatment duration $>2$ years, and the presence of anti-JCV antibodies as a fingerprint of JCV infection. If all 3 are present, the risk is around 1 per 90; if none is present it is around 1 per 10,000 [62]. Even for some time after the cessation of natalizumab, a certain risk of PML remains and pharmacovigilance should be continued $[63,64]$. There are increasing efforts to further refine PML risk stratification, especially for patients that convert to anti-JCV antibody positive status while on natalizumab, using antibody indices in serum and cerebrospinal fluid, as well as other approaches [65-68]. 


\section{Alemtuzumab}

Alemtuzumab is the drug with a new mechanism of action most recently approved for RR-MS by the EMA in 2013 and somewhat later by FDA (actually, the most recently approved substance is pegIFN- $\beta$, in 2014). The monoclonal antibody existed for some time and was initially developed for chronic lymphatic leukemia (CLL) as MabCampath: Genzyme, Cambridge, MA. It depletes CD52-positive cells - B and T lymphocytes among others - and the idea of its mechanism of action is that it erases large parts of the circulating memory cells, including those prone to attack the CNS, and then reconstitutes without these cells or at least cells not programmed for attack, and with an increased population of regulatory $\mathrm{T}$ cells. Efficacy was shown to be high with a relapse reduction of roughly $50 \%$ compared with the active comparator high-dose, high-frequency subcutaneous IFN-1 $\beta$ a in2 different studies (CARE-MS I and CARE-MS II) [69, 70]. More than the phase III trials for natalizumab and fingolimod, CARE-MS II reflects "real-world" decision making because all patients of the study had been on first-line therapy before entry. The drug induces a sustained deletion of CD52-positive cells, which explains its mode of administration ( 5 consecutive days of infusions and 3 more infusions 1 year later). Alemtuzumab has never been tested against placebo, making it even more difficult to compare it with other substances. However, most neurologists view alemtuzumab's efficacy at least in the range of that of natalizumab and probably better than fingolimod, but controlled head-to-head studies are lacking. Importantly, efficacy seems to be maintained for years following delivery of 2 annual cycles. Several safety issues are of importance, namely the relatively high rate of developing secondary autoimmune phenomena. Autoimmune thyroiditis has been reported at a rate up to one-third of patients. Even more concerning but less frequent are idiopathic thrombocytopenic purpura and Goodpasture syndrome associated with glomerular basement membrane antibodies. These conditions can develop a while after the first dose of the drug which therefore warrants close and long-term monitoring of the patient (at least 2 years after initiation). Some instances of herpes virus reactivation have been observed (but no encephalitis) so that prophylactic aciclovir treatment is considered obligatory in the first 4 weeks after treatment initiation. Cases of PML have not been reported thus far in patients with MS, but only in hematological and transplantation indications [71-73]. Cases of listeria infections have been reported, some with a severe disease course [74]. Many of the safety issues (especially emergent autoimmune complications) are quite common but appear to follow a known temporal sequence. Usually, they can be dealt with satisfactorily if effective long-term monitoring is in place [75]. Taken together, alemtuzumab is a new approach, broadening the options in severe RR-MS [76, 77].

\section{Treatment Algorithms in RR-MS}

A general problem in creating a treatment algorithm is that active comparator studies are scarce or lacking. There are only a few studies comparing first-line DMTs with other first- or second-line DMTs and there are none comparing second-line therapies with each other. Hence, at least parts of any such an algorithm must be based on comparing placebo-controlled studies with each other. However, that comes with many statistical pitfalls, especially when comparing the first pivotal IFN and GA trials in the 1990s with the later trials of natalizumab, the oral drugs, and alemtuzumab. The earliest trials, for example, used the Poser criteria for MS diagnosis, and later the McDonald criteria and their revised versions were applied [78-80]. Furthermore, in more recent trials patients tend to have a milder disease course with lower annualized relapse rates, to list just a few of the systematic problems of cross-study comparisons [81]. Another possibility of comparison, yet also flawed, is retrospective database analyses. Here, we present our current personal view on what such an algorithm could look like.

One particular problem in MS immunotherapy that has been with us for many years now is the risk of PML [82-85]. The rare opportunistic and potentially fatal CNS infection with JCV caught the MS community's attention, especially because of its association with natalizumab. Around one-quarter of patients die; the others experience neurological disabilities to differing extents. Correct and early PML diagnosis using MRI is important [86]. The vast majority of cases so far have been natalizumab-associated but some cases have been reported in patients on monotherapy with DMF and fingolimod. PML greatly affects treatment decisions and has stirred up a lot of uncertainty among physicians and patients. Recent developments in stratifying patients have been helpful in decision making.

The vast majority of PML cases in MS have been associated with natalizumab. Risk stratification includes previous use of immunosuppressants, the duration of natalizumab treatment, and (especially important for treatment decisions) JCV status (positive or negative for JCV-specific IgG). Recently, this has been refined by introduction of JCV index, and the JCV index is used by more and more centers [65, 87]. Thistogether with an intensified MRI regimen - could open up treatment options, especially for JCV-positive patients.

However, some cases have also been observed with DMF and fingolimod monotherapy. With regard to DMF, 4 cases (out of $>170,000$ patients treated with DMF [88]) have been reported, and the EMA published new guidelines calling for regular lymphocyte counts, as most cases of PML presented with counts $<500 / \mu 1$ [89]. However, the most recent case had counts between $500 / \mu l$ and $800 / \mu 1$, questioning the proposed guidelines. With regard to fingolimod monotherapy, 3 cases of PML have been reported so far (out of 125,000 patients treated 
with fingolimod) [54]. Here, patient stratification according to lymphocyte counts is not reasonable owing to the drug's unique mode of action, regularly associated with S1Pmediated therapeutic lymphopenia (with counts $<800 / \mu 1$ in the majority of patients).

\section{Initiation of Therapy}

Patients with de novo diagnosed RR-MS that have not been treated previously can choose between 4 first-line DMTs: the different preparations of IFN- $\beta$, GA, teriflunomide, and DMF. All of them can be considered more or less equally effective, with the exception and advantage of DMF, which in pivotal trials featured the largest reduction in relapse rates numerically (but was not statistically significantly better than the active comparator GA). If compliance is an issue, the oral drugs teriflunomide and DMF may be preferred; once-daily teriflunomide might be even more attractive than twice-daily DMF. If the patient is concerned about rare and maybe even not-yet-known adverse effects, the injectables might be a good choice because of the years of experience with these drugs. Also, women with child-bearing potential that plan to become pregnant, or at least keep open the possibility of becoming pregnant, may also opt for the injectables (in particular GA [13]). Women that are planning to become pregnant should probably not use teriflunomide. In any case, all these considerations must be discussed with patients in detail to enable them to decide individually.

Patients that are already on a first-line DMT may encounter tolerability issues and want to switch to another first-line DMT. Frequent are injection-related side effects in IFN- $\beta$ and GA, influenza-like symptoms in IFN- $\beta$, and flush or bowel-related adverse effects, for example, in DMF. The everyday life of these patients can benefit from today's growing DMT arsenal. In the face of breakthrough disease, however, most clinicians do not recommend switching from 1 baseline DMT to another as a growing bulk of evidence indicates that patients benefit from an early escalation [90].

\section{Escalation of Therapy}

In terms of escalation of therapy 2 questions have to be answered: 1) When do we consider an ongoing DMT ineffective or not effective enough and, 2) if we come to the conclusion that we have to switch therapies for efficacy reasons, which second-line therapy should be chosen?

Concerning the first question several approaches exist. Widely known is the so-called Rio Score, which was derived from analysis of long-term clinical data assessing the risk of substantial disability progression of patients using IFN- $\beta$ by taking 3 measures into account: relapses, new MRI lesions, and Expanded Disability Scale Score progression [91]. Depending on the combination of the 3 , recommendations on whether to switch or continue therapy can be based on statistics. The method was simplified later to the Modified Rio Score, relying on relapses and MRI measures only [92, 93]. For GA, DMF, and teriflunomide no such long-term data exist making it ultimately impossible for now to firmly base the decision of "not effective enough" for these drugs on evidence. However, in the absence of such data, it seems reasonable to us to extrapolate the method to the other first-line DMTs.

In recent years the concept of having a patient "free of disease activity" (i.e., no relapses, no MRI progression, no disability progression) was developed - initially in the context of the high efficacy of natalizumab [94]. Later, the term "no evidence of disease activity" was coined and is currently entering center stage in terms of evaluating efficacy data in prospective studies and also many post-hoc analyses of existing data on DMTs [95]. This paradigm also influences many clinicians and the trend goes to adopting a "zero tolerance" attitude. Clinicians recommend escalation of therapy at any hint of disease activity, also factoring in parameters such as brain atrophy rate, cognition, fatigue, depression, and quality of life. These are very interesting and much-noticed approaches, and such scores are likely to become important guidelines for treatment decisions, but most still have to prove their predictive value prospectively.

The second question, to which second-line therapy one should switch, has become increasingly complex, despite the fact that as of now, only 3 drugs are approved: natalizumab, fingolimod, and alemtuzumab. As stated before, direct comparisons are lacking, but looking at the existing data many clinicians and researchers view fingolimod as somewhat less effective while displaling a more favorable safety profile than alemtuzumab and natalizumab, monoclonal antibodies that are probably comparable in efficacy [96]. In line with this notion, a recent retrospective analysis from MSBase registry data provided evidence that a switch from injectables first-line DMTs to natalizumab provides better disease control than a switch from injectables to fingolimod [51]. Depending on the severity of breakthrough disease on first-line DMTs one might thus opt for fingolimod in less severe cases and natalizumab or alemtuzumab in more severe cases. In these severe cases natalizumab probably has a safety advantage over alemtuzumab provided no risk factors for PML are present (treatment duration, JCV antibody status, and previous immunosuppression). If JCV antibody status is positive many patients and clinicians may rather choose alemtuzumab.

\section{Switching Between Second-line Therapies}

Several issues can arise with patients on second-line DMTs that may lead to a switch from one second-line DMT to another. One reason can be the occurrence of relapses or deterioration of disability. Such breakthrough disease in fingolimod 


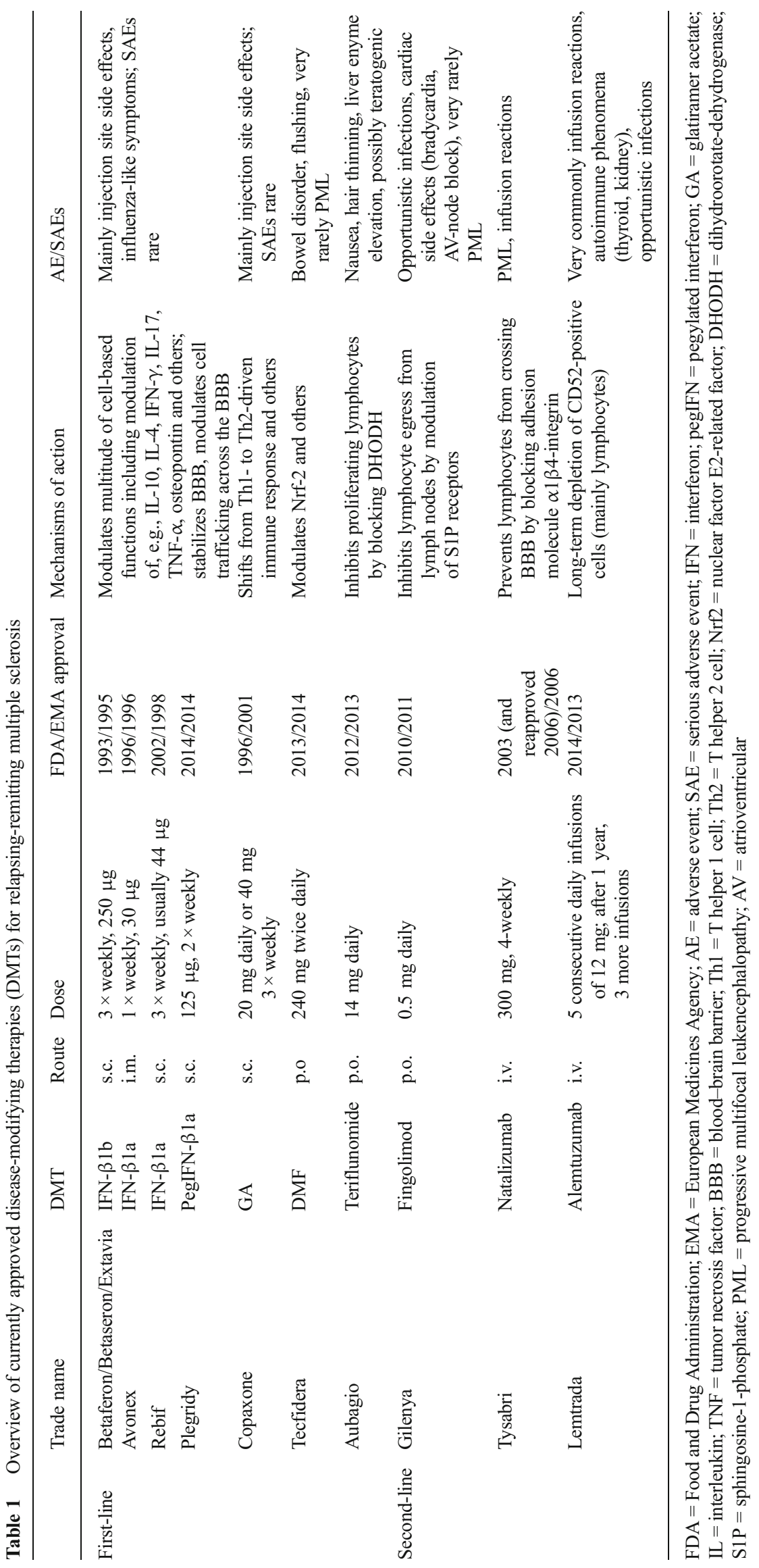


treatment would prompt consideration of an escalation to natalizumab or alemtuzumab, as delineated above. Breakthrough disease on either natalizumab or alemtuzumab could lead to switching to the other. One would probably not opt for fingolimod in that situation if the expected disease activity is very high despite very effective therapy. A few centers offer autologous stem cell transplantation in such a situation [97], but this approach is still in development and safety and efficacy still have to be assessed in larger cohorts. Breakthrough disease is, however, not the only reason for a need to switch therapies. Testing for JCV antibodies has greatly aided in stratification of PML risk in natalizumab treatment but has also generated the difficult question of what to do with a patient that is stable on natalizumab with no signs of PML but who has a positive JCV antibody test. Depending on treatment duration and previous immunosuppression, the risk may still be very low, but many patients want to change therapy in such a situation. The obvious candidate in this situation appears to be fingolimod which was recently shown to be advantageous over injectables after cessation of natalizumab [98], but is probably clinically less potent than natalizumab. Furthermore, some recent data strongly suggest that a switch from natalizumab to fingolimod may be associated with an increased risk of developing new disease activity [99, 100]. A recent report came to the conclusion that too-long washout phases between natalizumab discontinuation and fingolimod initiation may elevate that risk and recommends waiting 4-8 weeks between treatments [101]. There is still very limited experience of switching from natalizumab to alemtuzumab, and PML risk in JCV antibody-positive patients on alemtuzumab treatment after natalizumab is currently impossible to predict.

\section{Treating Aggressive MS}

According to their label, all 3 second-line drugs - fingolimod, natalizumab, and alemtuzumab - can also serve as treatment options in de novo patients if the disease course is considered highly active. Therefore, the classification as first line and second line is being questioned more and more, and some recommend a classification for mild/moderate and active/ highly active disease courses. There is no universal definition of "highly active" MS, though, but taking into account the labeling of the substances, it is generally defined by the occurrence of 2 relapses in the past year with disability progression and a significant increase of $\mathrm{T} 2$ lesions at critical locations (e.g., brainstem, cerebellum) on MRI [102]. In this setting, special attention must be paid to assessing the therapeutic risk in light of the expected efficacy of a drug [103]. Of course, all these considerations must be discussed with the patient extensively and joint decision-making should be entered, taking into account the patient's preferences.

\section{Conclusions}

Treatment options in RR-MS have increased considerably in recent years, with currently a dozen different preparations of

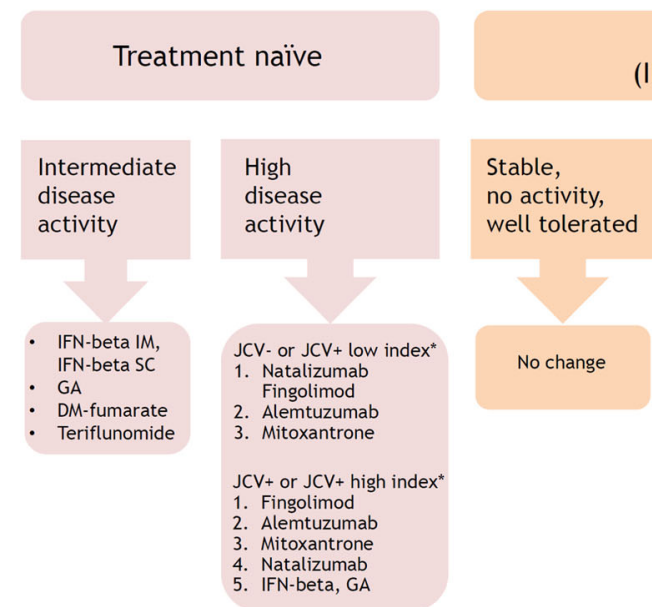

On baseline therapy

(IFN-beta, GA, DMF, Teri)

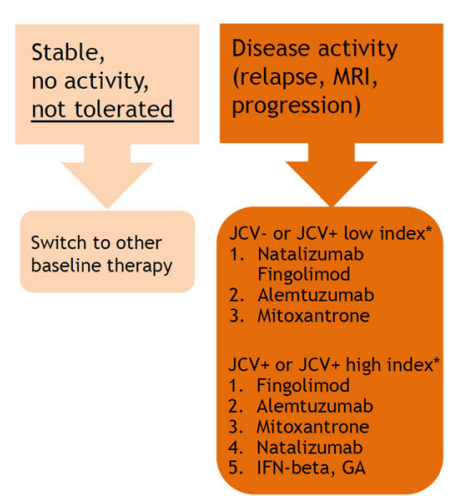

alemtuzumab. Patients that are already on baseline therapy can switch to another baseline DMT when encountering tolerability issues. At breakthrough disease, patients should be treated as patients with high disease activity (i.e., stratified by JCV antibody status). Modified according to [107]. *According to Plavina et al. antibody indices may accurately predict PML risk in natalizumab [65]. The index is increasingly used for stratification, but should be used with caution until validated in independent samples. $\mathrm{IM}=$ intramuscular; $\mathrm{SC}=$ subcutaneous; $\mathrm{DM}=$ dimethyl; $\mathrm{MRI}=$ magnetic resonance imaging 
DMTs available that exhibit differing efficacy, safety profiles, mechanisms of action, and modes of treatment, resulting in a quite complex landscape of individualized therapy in RRMS (Table 1). Herein, we have described current knowledge and experience with the existing therapies and suggest a treatment algorithm for most of the situations commonly encountered in clinical management (see Fig. 1). Further treatment options are being evaluated [2], and more knowledge about the safety profile of the existing DMTs is to be expected. In addition to ongoing developments regarding B- and T-celltargeted approaches combination therapies have been proposed in the past but remain an unresolved issue. Apart from economic considerations (the already high cost of all DMTs could be increased by combination preparations), only a few systematic approaches have been undertaken and have rather tamed enthusiasm: some were unsuccessful (e.g., CombiRx, comparing a combination of intramuscular IFN$1 \beta$ a plus GA with either 1 of the 2 [104]), or raised safety issues when combining 2 immunomodulatory agents (e.g., PML cases in SENTINEL comparing natalizumab plus intramuscular IFN- $1 \beta$ a with IFN- $\beta$ alone). An interesting approach, however, may be the combination of immunomodulatory agents with neuroprotective ones like LINGO-1 [105, 106]. The field of stratification of patients to the optimal DMT is also developing with so far only some rough approximations (e.g., JCV status, planned pregnancy). Further research is required for profiling patients, for example to T- or B cell-targeted approaches or to susceptibility for specific infectious side effects. The landscape is therefore going to evolve and new information has to be incorporated constantly into the management decisions that we make.

Required Author Forms Disclosure forms provided by the authors are available with the online version of this article.

\section{References}

1. Oh J, O'Connor PW. Novel and imminently emerging treatments in relapsing-remitting multiple sclerosis. Curr Opin Neurol 2015;28:230-236.

2. Stüve O. This issue.

3. Duquette P, Girard M, Despault L. Interferon beta- $1 \mathrm{~b}$ is effective in relapsing-remitting multiple sclerosis. I. Clinical results of a multicenter, randomized, double-blind, placebo-controlled trial. The IFNB Multiple Sclerosis Study Group. Neurology 1993;43: 655-661.

4. Jacobs LD, Cookfair DL, Rudick RA, et al. Intramuscular interferon beta-1a for disease progression in relapsing multiple sclerosis. The Multiple Sclerosis Collaborative Research Group (MSCRG). Ann Neurol 1996;39:285-294.

5. PRISMS Study Group. Randomised double-blind placebo-controlled study of interferon beta-1a in relapsing/remitting multiple sclerosis. PRISMS (Prevention of Relapses and Disability by
Interferon beta-1a Subcutaneously in Multiple Sclerosis) Study Group. Lancet 1998;352:1498-1504.

6. Calabresi PA, Kieseier BC, Arnold DL, et al. Pegylated interferon $\beta-1$ a for relapsing-remitting multiple sclerosis (ADVANCE): a randomised, phase 3, double-blind study. Lancet Neurol 2014;13:657-665.

7. Koch-Henriksen N, Sørensen PS, Christensen T, et al. A randomized study of two interferon-beta treatments in relapsing-remitting multiple sclerosis. Neurology 2006;66:1056-1060.

8. Kieseier BC. The mechanism of action of interferon- $\beta$ in relapsing multiple sclerosis. CNS Drugs 2011;25:491-502.

9. Johnson KP, Brooks BR, Cohen JA, et al. Copolymer 1 reduces relapse rate and improves disability in relapsing-remitting multiple sclerosis: results of a phase III multicenter, double-blind placebocontrolled trial. The Copolymer 1 Multiple Sclerosis Study Group. Neurology 1995;45:1268-1276.

10. Khan O, Rieckmann P, Boyko A, Selmaj K, Zivadinov R. Three times weekly glatiramer acetate in relapsing-remitting multiple sclerosis. Ann Neurol 2013;73:705-713.

11. Aharoni R. Immunomodulation neuroprotection and remyelination - the fundamental therapeutic effects of glatiramer acetate: a critical review. J Autoimmun 2014;54:81-92.

12. Edgar CM, Brunet DG, Fenton P, McBride EV, Green P. Lipoatrophy in patients with multiple sclerosis on glatiramer acetate. Can J Neurol Sci 2004;31:58-63.

13. Lu E, Wang BW, Guimond C, Synnes A, Sadovnick D, Tremlett H. Disease-modifying drugs for multiple sclerosis in pregnancy: a systematic review. Neurology 2012;79:1130-1135.

14. Linker RA, Lee D, Ryan S, et al. Fumaric acid esters exert neuroprotective effects in neuroinflammation via activation of the $\mathrm{Nrf} 2$ antioxidant pathway. Brain 2011;134:678-692.

15. Scannevin RH, Chollate S, Jung M, et al. Fumarates promote cytoprotection of central nervous system cells against oxidative stress via the nuclear factor (erythroid-derived 2)-like 2 pathway. J Pharmacol Exp Ther 2012;341:274-284.

16. Chen H, Assmann JC, Krenz A, et al. Hydroxycarboxylic acid receptor 2 mediates dimethyl fumarate's protective effect in EAE. J Clin Invest 2014;124:2188-2192.

17. Gold R, Kappos L, Arnold DL, et al. Placebo-controlled phase 3 study of oral BG-12 for relapsing multiple sclerosis. N Engl J Med 2012;367:1098-1107.

18. Viglietta V, Miller D, Bar-Or A, et al. Efficacy of delayed-release dimethyl fumarate in relapsing-remitting multiple sclerosis: integrated analysis of the phase 3 trials. Ann Clin Transl Neurol 2015;2:103-118.

19. Miller DH, Fox RJ, Phillips JT, et al. Effects of delayed-release dimethyl fumarate on MRI measures in the phase 3 CONFIRM study. Neurology 2015;84:1145-1152.

20. Fox RJ, Miller DH, Phillips JT, et al. Placebo-controlled phase 3 study of oral BG-12 or glatiramer in multiple sclerosis. N Engl J Med 2012;367:1087-1097.

21. Ermis U, Weis J, Schulz JB. PML in a patient treated with fumaric acid. N Engl J Med 2013;368:1657-1658.

22. van Oosten, Bob W, Killestein J, Barkhof F, Polman CH, Wattjes MP. PML in a patient treated with dimethyl fumarate from a compounding pharmacy. N Engl J Med 2013;368:1658-1659.

23. Rosenkranz T, Novas M, Terborg C. PML in a patient with lymphocytopenia treated with dimethyl fumarate. N Engl J Med 2015;372:1476-1478.

24. Nieuwkamp DJ, Murk J, van Oosten, et al. PML in a patient without severe lymphocytopenia receiving dimethyl fumarate. $\mathrm{N}$ Engl J Med 2015;372:1474-1476.

25. Dubey D, Kieseier BC, Hartung HP, et al. Dimethyl fumarate in relapsing-remitting multiple sclerosis: rationale, mechanisms of action, pharmacokinetics, efficacy and safety. Expert Rev Neurother 2015;15:339-346. 
26. Sheremata W, Brown AD, Rammohan KW. Dimethyl fumarate for treating relapsing multiple sclerosis. Expert Opin Drug Saf 2015;14:161-170.

27. Osiri M, Shea B, Robinson V, et al. Leflunomide for treating rheumatoid arthritis. Cochrane Database Syst Rev 2003: CD002047.

28. Claussen MC, Korn T. Immune mechanisms of new therapeutic strategies in MS: teriflunomide. Clin Immunol 2012;142:49-56.

29. Fairbanks LD, Bofill M, Ruckemann K, Simmonds HA. Importance of ribonucleotide availability to proliferating Tlymphocytes from healthy humans. Disproportionate expansion of pyrimidine pools and contrasting effects of de novo synthesis inhibitors. J Biol Chem 1995;270:29682-29689.

30. O'Connor P, Wolinsky JS, Confavreux C, et al. Randomized trial of oral teriflunomide for relapsing multiple sclerosis. $\mathrm{N}$ Engl J Med 2011;365:1293-1303.

31. Confavreux C, O'Connor $\mathrm{P}, \mathrm{Comi} \mathrm{G}$, et al. Oral teriflunomide for patients with relapsing multiple sclerosis (TOWER): a randomised, double-blind, placebo-controlled, phase 3 trial. Lancet Neurol 2014;13:247-256.

32. Vermersch P, Czlonkowska A, Grimaldi, et al. Teriflunomide versus subcutaneous interferon beta-1 $\mathrm{a}$ in patients with relapsing multiple sclerosis: a randomised, controlled phase 3 trial. Mult Scler 2014;20:705-716.

33. Warnatz K, Peter HH, Schumacher M, et al. Infectious CNS disease as a differential diagnosis in systemic rheumatic diseases: three case reports and a review of the literature. Ann Rheum Dis 2003;62:50-57.

34. Rahmlow M, Shuster EA, Dominik J, et al. Leflunomideassociated progressive multifocal leukoencephalopathy. Arch Neurol 2008;65:1538-1539.

35. Schmedt N, Andersohn F, Garbe E. Signals of progressive multifocal leukoencephalopathy for immunosuppressants: a disproportionality analysis of spontaneous reports within the US Adverse Event Reporting System (AERS). Pharmacoepidemiol Drug Saf 2012;21:1216-1220.

36. Kieseier BC, Benamor M. Pregnancy outcomes following maternal and paternal exposure to teriflunomide during treatment for relapsing-remitting multiple sclerosis. Neurol Ther 2014;3: 133-138.

37. Sartori A, Carle D, Freedman MS. Teriflunomide: a novel oral treatment for relapsing multiple sclerosis. Expert Opin Pharmacother 2014;15:1019-1027.

38. Ingwersen J, Aktas O, Kuery P, Kieseier B, Boyko A, Hartung H. Fingolimod in multiple sclerosis: mechanisms of action and clinical efficacy. Clin Immunol 2012;142:15-24.

39. Prager B, Spampinato SF, Ransohoff RM. Sphingosine 1phosphate signaling at the blood-brain barrier. Trends Mol Med 2015;21:354-363.

40. Miron VE, Jung CG, Kim HJ, Kennedy TE, Soliven B, Antel JP. FTY720 modulates human oligodendrocyte progenitor process extension and survival. Ann Neurol 2008;63:61-71.

41. Choi JW, Gardell SE, Herr DR, et al. FTY720 (fingolimod) efficacy in an animal model of multiple sclerosis requires astrocyte sphingosine 1-phosphate receptor 1 (S1P1) modulation. Proc Natl Acad Sci U S A 2011;108:751-756.

42. Kim HJ, Miron VE, Dukala D, et al. Neurobiological effects of sphingosine 1-phosphate receptor modulation in the cuprizone model. FASEB J 2011;25:1509-1518.

43. Lublin F, Miller D, Freedman M, et al. Oral fingolimod versus placebo in primary progressive multiple sclerosis: results of INFORMS, a large phase III, randomized, double-blind, placebo-controlled trial. Lancet 2016 (in press).

44. Kappos L, Radue E, O'Connor P, et al. A placebo-controlled trial of oral fingolimod in relapsing multiple sclerosis. N Engl J Med 2010;362:387-401.
45. Calabresi PA, Radue E, Goodin D, et al. Safety and efficacy of fingolimod in patients with relapsing-remitting multiple sclerosis (FREEDOMS II): a double-blind, randomised, placebocontrolled, phase 3 trial. Lancet Neurol 2014;13:545-556.

46. Devonshire V, Havrdova E, Radue EW, et al. Relapse and disability outcomes in patients with multiple sclerosis treated with fingolimod: subgroup analyses of the double-blind, randomised, placebo-controlled FREEDOMS study. Lancet Neurol 2012;11: 420-428.

47. Radue E, O'Connor P, Polman $\mathrm{CH}$, et al. Impact of fingolimod therapy on magnetic resonance imaging outcomes in patients with multiple sclerosis. Arch Neurol 2012;69:1259-1269.

48. Cohen JA, Barkhof F, Comi G, et al. Oral fingolimod or intramuscular interferon for relapsing multiple sclerosis. N Engl J Med 2010;362:402-415.

49. Bergvall N, Makin C, Lahoz R, et al. Relapse rates in patients with multiple sclerosis switching from interferon to fingolimod or glatiramer acetate: a US claims database study. PLoS ONE 2014;9:e88472.

50. Nixon R, Bergvall N, Tomic D, Sfikas N, Cutter G, Giovannoni G. No evidence of disease activity: indirect comparisons of oral therapies for the treatment of relapsing-remitting multiple sclerosis. Adv Ther 2014;31:1134-1154.

51. Kalincik T, Horakova D, Spelman T, et al. Switch to natalizumab versus fingolimod in active relapsing-remitting multiple sclerosis. Ann Neurol 2015;77:425-435.

52. Huang D. Disseminated cryptococcosis in a patient with multiple sclerosis treated with fingolimod. Neurology 2015; 85: 1001-1003.

53. Arvin AM, Wolinsky JS, Kappos L, et al. Varicella-zoster virus infections in patients treated with fingolimod: risk assessment and consensus recommendations for management. JAMA Neurol 2015;72:31-39.

54. Novartis AG. Gilenya Information Center. Available at: https:// www.novartis.com/news/statements/gilenya-information-center. Accessed August 17, 2015.

55. Polman $\mathrm{CH}, \mathrm{O}^{\prime}$ Connor $\mathrm{PW}$, Havrdova E, et al. A randomized, placebo-controlled trial of natalizumab for relapsing multiple sclerosis. N Engl J Med 2006;354:899-910.

56. Langer-Gould A, Atlas SW, Green AJ, Bollen AW, Pelletier D. Progressive multifocal leukoencephalopathy in a patient treated with natalizumab. N Engl J Med 2005;353:375-381.

57. Kleinschmidt-DeMasters BK, Tyler KL. Progressive multifocal leukoencephalopathy complicating treatment with natalizumab and interferon beta-1a for multiple sclerosis. N Engl J Med 2005;353:369-374.

58. Butzkueven H, Kappos L, Pellegrini F, et al. Efficacy and safety of natalizumab in multiple sclerosis: interim observational programme results. J Neurol Neurosurg Psychiatr 2014;85:11901197.

59. Aktas O. Natalizumab in clinical practice: managing the risks, enjoying the benefits. J Neurol Neurosurg Psychiatr 2014;85: 1181.

60. Spelman T, Kalincik T, Zhang A, et al. Comparative efficacy of switching to natalizumab in active multiple sclerosis. Ann Clin Transl Neurol 2015;2:373-387.

61. Biogen. TYSABRI ${ }^{\circledR}$ (natalizumab): PML incidence in patients receiving TYSABRI. Available at: http://www.biogen.com. Accessed September 4, 2015.

62. Bloomgren $\mathrm{G}$, Richman $\mathrm{S}$, Hotermans $\mathrm{C}$, et al. Risk of natalizumabassociated progressive multifocal leukoencephalopathy. N Engl J Med 2012;366:1870-1880.

63. Fine AJ, Sorbello A, Kortepeter C, Scarazzini L. Progressive multifocal leukoencephalopathy after natalizumab discontinuation. Ann Neurol 2014;75:108-115. 
64. Wattjes MP, Killestein J. Progressive multifocal leukoencephalopathy after natalizumab discontinuation: few and true? Ann Neurol 2014;75:462.

65. Plavina T, Subramanyam M, Bloomgren G, et al. Anti-JC virus antibody levels in serum or plasma further define risk of natalizumab-associated progressive multifocal leukoencephalopathy. Ann Neurol 2014;76:802-812.

66. Schwab N, Schneider-Hohendorf T, Posevitz V, et al. L-selectin is a possible biomarker for individual PML risk in natalizumabtreated MS patients. Neurology 2013;81:865-871.

67. Villar LM, Costa-Frossard L, Masterman T, et al. Lipid-specific immunoglobulin $\mathrm{M}$ bands in cerebrospinal fluid are associated with a reduced risk of developing progressive multifocal leukoencephalopathy during treatment with natalizumab. Ann Neurol 2015;77:447-457.

68. Warnke C, von Geldern G, Markwerth P, et al. Cerebrospinal fluid $\mathrm{JC}$ virus antibody index for diagnosis of natalizumab-associated progressive multifocal leukoencephalopathy. Ann Neurol 2014;76:792-801.

69. Cohen JA, Coles AJ, Arnold DL, et al. Alemtuzumab versus interferon beta 1a as first-line treatment for patients with relapsingremitting multiple sclerosis: a randomised controlled phase 3 trial. Lancet 2012;380:1819-1828.

70. Coles AJ, Twyman CL, Arnold DL, et al. Alemtuzumab for patients with relapsing multiple sclerosis after disease-modifying therapy: a randomised controlled phase 3 trial. Lancet 2012;380: 1829-1839.

71. Havrdova E, Horakova D, Kovarova I. Alemtuzumab in the treatment of multiple sclerosis: key clinical trial results and considerations for use. Ther Adv Neurol Disord 2015;8:31-45.

72. Waggoner J, Martinu T, Palmer SM. Progressive multifocal leukoencephalopathy following heightened immunosuppression after lung transplant. J Heart Lung Transplant 2009;28: 395-398.

73. Isidoro L, Pires P, Rito L, Cordeiro G. Progressive multifocal leukoencephalopathy in a patient with chronic lymphocytic leukaemia treated with alemtuzumab. BMJ Case Rep 2014;2014.

74. Rau D, Lang M, Harth A, et al. Listeria meningitis complicating alemtuzumab treatment in multiple sclerosis-report of two cases. Int J Mol Sci 2015;16:14669-14676.

75. Willis MD, Robertson NP. Alemtuzumab for the treatment of multiple sclerosis. Ther Clin Risk Manag 2015;11:525-534.

76. Hartung H, Aktas O, Boyko AN. Alemtuzumab: a new therapy for active relapsing-remitting multiple sclerosis. Mult Scler 2015;21: 22-34.

77. Menge T, Stüve O, Kieseier BC, Hartung H. Alemtuzumab: the advantages and challenges of a novel therapy in MS. Neurology 2014;83:87-97.

78. McDonald WI, Compston A, Edan G, et al. Recommended diagnostic criteria for multiple sclerosis: guidelines from the International Panel on the diagnosis of multiple sclerosis. Ann Neurol 2001;50:121-127.

79. Polman CH, Reingold SC, Edan G, et al. Diagnostic criteria for multiple sclerosis: 2005 revisions to the "McDonald Criteria". Ann Neurol 2005;58:840-846.

80. Polman CH, Reingold SC, Banwell B, et al. Diagnostic criteria for multiple sclerosis: 2010 revisions to the McDonald criteria. Ann Neurol 2011:69:292-302.

81. Klawiter EC, Cross AH, Naismith RT. The present efficacy of multiple sclerosis therapeutics: Is the new $66 \%$ just the old 33\%? Neurology 2009;73:984-990.

82. Baldwin KJ, Hogg JP. Progressive multifocal leukoencephalopathy in patients with multiple sclerosis. Curr Opin Neurol 2013;26: 318-323.
83. Warnke C, Olsson T, Hartung H. PML: The dark side of immunotherapy in multiple sclerosis. Trends Pharmacol Sci 2015.

84. Chahin S, Berger JR. A risk classification for immunosuppressive treatment-associated progressive multifocal leukoencephalopathy. J Neurovirol 2015;21:623-631.

85. Faulkner M. Risk of progressive multifocal leukoencephalopathy in patients with multiple sclerosis. Expert Opin Drug Saf 2015;14: 1737-1748.

86. Wattjes MP, Barkhof F. Diagnosis of natalizumab-associated progressive multifocal leukoencephalopathy using MRI. Curr Opin Neurol 2014;27:260-270.

87. McGuigan C, Craner M, Guadagno J, et al. Stratification and monitoring of natalizumab-associated progressive multifocal leukoencephalopathy risk: recommendations from an expert group. J Neurol Neurosurg Psychiatr 2015 (in press).

88. Biogen. Tecfidera (dimethyl fumarate). Available at: http://www. tecfiderahcp.com. Accessed November 20, 2015.

89. European Medicines Agency. Updated recommendations to minimise the risk of the rare brain infection PML with Tecfidera. Available at: http://www.ema.europa.eu/ema/index.jsp?curl= pages/news and events/news/2015/10/news detail 002423 . jsp\&mid $=\overline{W C} 0 \mathrm{~b} 01$ ac $058004 \mathrm{~d} 5 \mathrm{c} 1$. Accessd October 23, 2015.

90. Stüve O, Centonze D. Treatment decisions for patients with active multiple sclerosis. JAMA Neurol 2015;72:387-389.

91. Río J, Castilló J, Rovira A, et al. Measures in the first year of therapy predict the response to interferon beta in MS. Mult Scler 2009;15:848-853.

92. Sormani MP, Rio J, Tintorè M, et al. Scoring treatment response in patients with relapsing multiple sclerosis. Mult Scler 2013;19:605-612.

93. Sormani M, Signori A, Stromillo M, de Stefano N. Refining response to treatment as defined by the Modified Rio Score. Mult Scler 2013;19:1246-1247.

94. Havrdova E, Galetta S, Hutchinson M, et al. Effect of natalizumab on clinical and radiological disease activity in multiple sclerosis: a retrospective analysis of the Natalizumab Safety and Efficacy in Relapsing-Remitting Multiple Sclerosis (AFFIRM) study. Lancet Neurol 2009;8:254-260.

95. Bevan CJ, Cree, Bruce A C. Disease activity free status: a new end point for a new era in multiple sclerosis clinical research? JAMA Neurol 2014;71:269-270.

96. Hauser SL, Chan JR, Oksenberg JR. Multiple sclerosis: Prospects and promise. Ann Neurol 2013;74:317-327.

97. Mancardi GL, Sormani MP, Gualandi F, et al. Autologous hematopoietic stem cell transplantation in multiple sclerosis: a phase II trial. Neurology 2015;84:981-988.

98. Iaffaldano P, Lucisano G, Pozzilli C, et al. Fingolimod versus interferon beta/glatiramer acetate after natalizumab suspension in multiple sclerosis. Brain 2015;138:3275-3286.

99. Cohen M, Maillart E, Tourbah A, et al. Switching from natalizumab to fingolimod in multiple sclerosis: a French prospective study. JAMA Neurol 2014;71:436-441.

100. Hoepner R, Havla J, Eienbröker C, et al. Predictors for multiple sclerosis relapses after switching from natalizumab to fingolimod. Mult Scler 2014;20:1714-1720.

101. Kappos L, Radue E, Comi G, et al. Switching from natalizumab to fingolimod: A randomized, placebo-controlled study in RRMS. Neurology 2015;85:29-39.

102. Rush CA, MacLean HJ, Freedman MS. Aggressive multiple sclerosis: proposed definition and treatment algorithm. Nat Rev Neurol 2015;11:379-389.

103. Clanet MC, Wolinsky JS, Ashton RJ, Hartung H, Reingold SC. Risk evaluation and monitoring in multiple sclerosis therapeutics. Mult Scler 2014;20:1306-1311. 
104. Lublin FD, Cofield SS, Cutter GR, et al. Randomized study combining interferon and glatiramer acetate in multiple sclerosis. Ann Neurol 2013;73:327-340.

105. Cadavid D, Balcer L, Galetta S, et al. Efficacy Analysis of the AntiLINGO-1 Monoclonal Antibody BIIB033 in Acute Optic Neuritis: the RENEW Trial (P7. 202). Neurology 2015;84(Suppl. 14).
106. Aktas O, Vanopdenbosch L, Comi G, et al. Anti-LINGO-1 monoclonal antibody BIIB033 improves optic nerve latency in acute optic neuritis: primary efficacy analysis of the RENEW study. ECTRIMS Online Library 2015:116669.

107. Sorensen PS. New management algorithms in multiple sclerosis. Curr Opin Neurol 2014;27:246-259. 